Понятие и виды мер государственного принуждения: сравнительный анализ концепций дореволюционного и современного периодов

\author{
А. М. КОЛОСКОВ - доцент кафедры административно-правовых \\ дисциплин юридического фракультета ВИПЭ ФСИН России, кан- \\ дидат юридических наук, доцент
}
О. Р. ШИХНАБИЕВА - консультант отдела строительства и транс- порта Управления ЖКХ, строительства и транспорта, архитекту- ры и градостроительства администрации Шекснинского муници- пального района;

\begin{abstract}
В статье исследуются различные подходы к определению понятия государственного принуждения и классификации его мер. Предпринимается попытка сравнительного анализа воззрений отечественных правоведов начала XX в. и представлений современных российских ученых о типологизации мер государственного принуждения; рассматриваются общие и отличительные черты во взглядах современных исследователей.
\end{abstract}

Ключе в ы е слова: принуждение; государственное принуждение; меры принуждения; классификация мер государственного принуждения.

12.00.01 - Теория и история права и государства; история учений о праве и государстве.

Для ци ти ров ания: Колосков А. М., Шихнабиева О. Р. Понятие и виды мер государственного принуждения: сравнительный анализ концепций дореволюционного и современного периодов. Ius publicum et privatum : сетевой научно-практический журнал частного и публичного права, 2021, № 1 (11), с. 14-19, DOI 10.46741/27132811-2021-1-14-19.

\title{
The concepts and types of measures of state coercion: a comparative analysis of the concepts of the pre-revolutionary and modern periods
}

\begin{abstract}
A. M. KOLOSKOV - Associate Professor of the Department of Administrative and Legal Disciplines of the Vologda Institute of Law and Economics of the Federal Penal Service of Russia, PhD. in Law, Associate Professor
\end{abstract}

O. R. SHIKHNABIEVA - Consultant of the Construction and Transport Department of the Housing and Utilities Administration, Construction and Transport, Architecture and Urban Planning Administration of the Sheksninsky Municipal District Administration;

\footnotetext{
The article examines various approaches to defining the concept of state coercion and classifying its measures. An attempt is made to perform a comparative analysis of the views of Russian jurists at the beginning of the 20th century and the ideas of modern Russian scientists about the typology of measures of state coercion; common and distinctive features in the views of modern researchers are considered.
} 
Key words: coercion; state coercion; coercive measures; classification of measures of state coercion.

12.00.01 - Theory and history of law and state; history of doctrines about law and state.

F or c it ation: Koloskov. A. M., Shikhnabieva O. R. The concepts and types of measures of state coercion: a comparative analysis of the concepts of the pre-revolutionary and modern periods. Ius publicum et privatum : online scientific and practical journal of private and public law, 2021, no. 1 (11), pp. 14-19, DOI 10.46741/2713-2811-2021-1-14-19.

Государственное принуждение традиционно рассматривается как применение государственными органами и должностными лицами специальных мер воздействия на лиц, обязанных выполнять возложенные на них обязанности и соблюдать запреты, установленные законодательством.

Роль государственного принуждения состоит в защите прав и интересов граждан и организаций, охране правопорядка и собственности, создании условий для деятельности органов власти. Именно поэтому основной целью государственного принуждения является обеспечение устойчивого правопорядка в обществе, сохранность прав и свобод человека и гражданина.

В науке существует множество различных точек зрения на суть понятия государственного принуждения. Так, П. В. Глаголев рассматривает государственное принуждение как правовые средства государства для защиты общественных отношений, которые складываются во всех сферах жизнедеятельности, от противоправных посягательств с целью предотвращения возникновения обстоятельств, угрожающих личной и общественной безопасности граждан, юридических лиц и общества в целом'.

Д. Н. Бахрах считает, что государственное принуждение - это своего рода реакция органов власти на опасное и незаконное поведение отдельных лиц. Применение принуждения вызывает конфликт между волей, выраженной в законе, и индивидуальной волей тех, кто его нарушает². Другими словами, государственное принуждение применяется к субъектам права, нарушившим правовые нормы.

Таким образом, государственное принуждение осуществляется в области защиты общественных отношений, складывающихся в различных сферах общественной жизни, от любых посягательств, опасных и нарушающих закондействий. Его цель - предупреждение совершения противоправных действий и предотвращение возникновения нежелательных для общественной жизни, безопасности граждан, правопорядка, общества и государства в целом обстоятельств.
Как и любой механизм, государственное принуждение имеет свой инструмент воздействия - меры государственного принуждения.

А. И. Каплунов отмечает, что меры принуждения - это установленные законом способы, приемы, средства и действия, позволяющие заставить лицо исполнять юридические обязанности и соблюдать правовые запреты, либо это дополнительные обременения в связи с совершением лицом противоправных деяний. Их применение обеспечивает предупреждение и пресечение правонарушений, привлечение виновных лиц к ответственности, восстановление нарушенных субъективных прав, защиту личности и ее имущества от источника опасности ${ }^{3}$.

Мы считаем, что меры принуждения - это инструменты государственных органов и должностных лиц для осуществления воздействия на субъектов для предотвращения или прекращения их деяний, нарушающих установленные законодательством запреты.

Некоторые исследователи фактически отождествляют меры и формы государственного принуждения, классифицируемые по следующим основаниям:

- по предмету правового регулирования (уголовно-правовое, гражданско-правовое, административно-правовое и другое принуждение);

- предметному содержанию направленности правовых ограничений (физическое, имущественное, организационное и другое принуждение);

- субъектам применения (судебное, внесудебное, общественное принуждение);

- нормативным основаниям (материально-правовое, процедурно-процессуальное принуждение);

- фактическим основаниям применения (предупредительные (превентивные) меры, пресечение, восстановление, юридическая ответственность) ${ }^{4}$.

Попытки классифицировать меры государственного принуждения предпринимались отечественными юристами еще в 
конце XIX в. Так, к примеру, Е. Н. Трубецкой в качестве критерия разделения использовал отношение принуждения к праву, то есть выделял правомерное (исходящее из признанной правом власти) и неправомерное (применяемое самозваными властями) принуждение ${ }^{5}$.

Проведя глубокий анализ общественных отношений, которые связаны с применением, способами реализации, видами и целями государственного принуждения, и исходя из того, что эти меры относятся к средствам правоохраны, профессор А. А. Жижиленко в свою классификацию включил меры предупреждения противоправного деяния («неправды») и меры, направленные на устранение «правовых последствий» противоправного деяния ${ }^{6}$.

Главной отличительной чертой приведенной классификации является то, что меры предупреждения направлены на создание условий, затрудняющих появление опасного деяния, а меры устранения, в свою очередь, используются как реакция на уже сбывшееся или действующее противоправное деяние.

Что касается широкого спектра правовых последствий противоправных действий, то А. А. Жижиленко было предложено разделить меры устранения в зависимости от их функций и цели на четыре группы: санкции, меры пресечения, меры защиты, меры по предотвращению и возмещению ущерба.

Особую роль в пресечении противоправных действий А. А. Жижиленко отводил предусмотренным законодательством Российской империи мерам государственного принуждения, которые он сгруппировал следующим образом:

- использование оружия;

- меры по ликвидации;

- привод;

- меры задержания.

Весомый вклад в разработку классификации мер государственного принуждения внесли в XX в. ученые-полицеисты, которые выделили характеристики полицейского государства и определяющие формы позитивной (без использования мер государственного принуждения) и негативной (с применением государственных мер принуждения) полицейской деятельности ${ }^{7}$.

Стоит отметить, что большинство существующих в настоящее время исследований в сфере классификации мер государственного принуждения построено на трудах профессора И. Т. Тарасова ${ }^{8}$, изучавшего проблему функционирования институтов государственной власти и, в частности, вопросы государственного принуждения как ее составляющие. Его классификация форм государственного принуждения, применяемых органами власти, включала четыре группы:

1) использование судебной власти в качестве средства принуждения сотрудниками правоохранительных органов и органов власти;

2) личное задержание;

3) принуждение с использованием оружия;

4) исключительное, осадное или чрезвычайное (военное) положение ${ }^{9}$.

В начале XX в. мир испытал серьезные потрясения. Изменились хозяйственная жизнь и экономика, облик городов. Значимые перемены произошли в политической жизни общества, в которую теперь были вовлечены не только представители власти, но и широкие народные массы. В этот период активно развивалась и полицейско-правовая теория, в рамках которой государственное принуждение рассматривалось как одно из средств государственного управления обществом, когда органы власти и их должностные лица осуществляют свои полномочия по предотвращению опасности, препятствующей развитию благосостояния граждан. Деятельность полиции осуществлялась в двух направлениях: 1) административная деятельность по устранению угрозы лишь для определенной сферы и отрасли жизнедеятельности; 2) обеспечение безопасности государства как целостного образования.

По мнению А. Е. Назимова, при ограничении личных и имущественных прав граждан применяются меры принуждения, выражающиеся в предупреждении, пресечении и устранении угрозы нарушения чужих прав и интересов ${ }^{10}$.

Начало XX в. богато на исследования в области государственного управления вообще и государственного принуждения в частности. Так, профессор В. В. Ивановский предложил следующую классификацию принудительных мер, оказывающих наибольшее влияние на личность человека и применяемых органами исполнительной власти в сфере правоохранительной деятельности:

1. Отчуждение вида на жительство, требование явки, привод, запрет на выезды.

2. Полицейский надзор не только как превентивная мера полиции, но и как суровая внесудебная санкция, связанная со значительными ограничениями правоспособности подследственных. 
3. Полицейский арест, применяемый как мера пресечения и мера предупреждения.

4. Использование оружия, выражающееся в двух формах: применение оружия полицией и использование военной силы по приказу гражданской администрации.

5. Исключительное (военное) положение как мера государственного принуждения с применением специальных законов, направленная на целые группы лиц (поселение, город) и используемая как повышенная охрана для сохранения государственного порядка ${ }^{11}$.

Еще один представитель полицеистики начала XX в. М. Н. Палибин ${ }^{12}$ рассматривал полицейскую деятельность как вид государственной или иной деятельности, направленной на создание «условий безопасности и благополучия, без которых развитие личности не представляется возможным». При этом он выделял несколько мер государственного принуждения: личное задержание, обыск домов и выемки, арест имущества, вскрытие частной переписки, принуждение с использованием оружия.

М. Н. Палибин считал, что в случае угрозы нарушения целостности и риска потери государством независимости, «когда от данной минуты зависит самое бытие государства», оно должно использовать специальные меры охраны, временно ограничив свободы граждан.

Таким образом, рассмотренные подходы ученых-юристов начала XX в. к классификации мер государственного принуждения отличаются разнообразием как критериев классификации, так и фактического содержания.

Особый интерес в рамках проводимого исследования представляют взгляды современных правоведов на классификацию мер государственного принуждения.

Так, А. И. Каплунов, П. В. Демидов ${ }^{13}$, Н. В. Макарейко ${ }^{14}$ и другие подразделяют меры государственного принуждения в зависимости от способов охраны правопорядка и обеспечения общественной безопасности на предупреждение, пресечение, правовосстановление, юридическую ответственность (наказание) и процессуальное обеспечение.

В свою очередь А. Ю. Анненков ${ }^{15}$, А. А. Васечко $^{16}$ и В. А. Чашников ${ }^{17}$ классифицируют меры государственного принуждения по таким критериям, как причины их применения (карательные или правовосстановительные), варианты поведения субъекта правопринуждения (физическое или пси- хологическое принуждение), закрепление в законодательстве (в законных или подзаконных актах) и круг лиц, к которым может быть применено принуждение.

Кроме того, меры государственного принуждения в современных научных публикациях, например работах А. Б. Агапова ${ }^{18}$, А. М. Волкова ${ }^{19}$ и других, часто подразделяют на меры предупредительного характера, носящие профилактический характер, меры пересечения, нацеленные на прекращение имеющихся и предотвращение новых противоправных деяний, и правовосстановительные меры, применяющиеся за проступки с минимальной степенью общественной опасности.

Особо следует отметить, что отраслевая принадлежность мер государственного принуждения обеспечивается спецификой правового регулирования. Так, меры административно-правового принуждения применяются в различных областях государственного управления. Например, соответствующие меры в сфере исполнения уголовных наказаний были изучены Р. В. Нагорных ${ }^{20}$, Н. А. Мельниковой ${ }^{21}$, Н. В. Анискиной ${ }^{22}$ и др.

Наиболее распространенной и устоявшейся классификацией мер государственного принуждения в теории государства и права является их разделение на предупредительные, пресекательные, меры защиты (правовосстановительные) и меры юридической ответственности. В то же время ряд ученых, в частности Д. Н. Бахрах, выделяют также меры процессуального обеспечения ${ }^{23}$.

Проанализировав различные точки зрения современников на классификацию мер государственного принуждения, можно сделать следующий вывод: перечисленные разделения по видам дают возможность определить индивидуальные особенности каждой из мер, выявить ее правовую природу, а также место и роль в правовом механизме.

И если в начале XX в. отмечалось многообразие подходов к группированию мер государственного принуждения, что обусловлено изменяющейся политической обстановкой в стране, появлением нового уклада государственного управления, то в современный период наблюдается единство мнений при незначительных различиях в отдельных деталях.

Таким образом, понятию и видам мер государственного принуждения уделяется значительное внимание со стороны 
ученых прошлого столетия и современных правоведов, что объясняется значимостью государственного принуждения как с точки зрения формирования стабильно функционирующего государственно- го аппарата, способного противостоять угрозам и вызовам действительности, так и с позиции обеспечения и защиты прав, свобод и законных интересов личности и общества.

\section{ПРИМЕЧАНИЯ}

${ }^{1}$ См.: Глаголев П. В. Юридическая ответственность в системе мер государственного принуждения : автореф. дис. ... канд. юрид. наук. Орел, 2007. 18 с.

${ }^{2}$ См.: Бахрах Д. Н., Российский Б. В., Старилов Ю. Н. Административное право : учеб. для вузов. 2-е изд., изм. и доп. М., 2005. 800 c.

${ }^{3}$ См.: Каплунов А. И. Административное принуждение, применяемое органами внутренних дел (системно-правовой анализ) : дис. .... д-ра юрид. наук. М., 2005. 498 с.

${ }^{4}$ См.: Сарсенов К. М. Государственное принуждение и его реализация в деятельности органов внутренних дел : автореф. дис. .... канд. юрид. наук. СПб., 1996. 196 с.

${ }^{5}$ См.: Трубецкой Е. Н. Лекции по энциклопедии права. М., 1917. 227 с.

${ }^{6}$ См.: Жижиленко А. А. Наказание: его понятие и отличие от других правоохранительных средств. Петроград, 1914. $684 \mathrm{c}$.

${ }_{7}$ См.: Нижник Н. С. Полицейско-правовая теория: основные этапы становления в России // Государство и право: эволюция, современное состояние, перспективы развития (навстречу 300-летию российской полиции) : материалы междунар. науч.-теорет. конф. (г. Санкт-Петербург, 28 апреля 2016 г.) : в 2 т. / под ред. Н. С. Нижник. СПб., 2016. T. 2. C. 230.

${ }^{8}$ См.: Тарасов Н. К. «Государственное принуждение»: трактовка дефиниции в юридической литературе конца XIX начала XX века // Право и государство: проблемы методологии, теории и истории : материалы VIII Всерос. науч.практ. конф. / ред. кол.: Л. В. Карнаушенко, А. А. Швец, Е. А. Пушкарев и др. Краснодар, 2019. С. 287.

${ }_{9}^{9}$ См.: Он же. Феномен «принуждение»: подходы к определению сущности в современной гуманитарной науке // Там же. С. 296.

${ }^{10}$ См.: Назимов А. Е. Лекции по полицейскому праву / под ред. студ. Б. Ф. Лемеша-Лемешинского. Одесса, 1903. C. $145-146$.

${ }_{11}$ См.: Ивановский В. В. Учебник административного права (Полицейское право. Право внутреннего управления). 3-е изд. Казань, 1908. С. 298.

${ }^{12}$ См.: Палибин М. Н. Повторительный курс полицейского права. 2-е изд. СПб., 1900. 255 с.

${ }^{13}$ См.: Демидов П. В. Частное правовое принуждение как категория современной теории права: научные и практические проблемы : дис. ... канд. юрид. наук. Н. Новгород, 2005. С. 78.

${ }^{14}$ См.: Макарейко Н. В. Государственное принуждение как средство обеспечения общественного порядка : дис. .... канд. юрид. наук. Н. Новгород, 1996. С. 102.

${ }^{15}$ См.: Анненков А. Ю. Государственно-правовое принуждение: философско-правовые основы понимания // Эконом. и юрид. науки. 2017. № 3-2. С. 52-60.

${ }^{16}$ См.: Васечко А. А. Международный договор как источник внутригосударственного права : дис. ... канд. юрид. наук. М., 2008.

17 См.: Чашников В. А. Государственно-правовое принуждение: общетеоретические вопросы : дис. ... канд. юрид. наук. Екатеринбург, 2006. С. 87.

${ }^{18}$ См.: Агапов А. Б. Административное право : учеб. для бакалавриата и магистратуры : в 2 т. М., 2019. Т. 1. Общая часть. 472 с.

${ }^{19}$ См.: Волков А. М. Административное право России : учеб. М., 2019. 328 с.

${ }^{20}$ См.: Нагорных Р. В. Административно-правовое принуждение // Сущность, формы и методы реализации исполнительной власти : учеб. пособие для магистратуры по направлению подготовки «Юрист в сфере государственного управления» / Васильева Я. В. и [др.]. Вологда, 2019. С. 133-155.

${ }_{21}$ См.: Мельникова Н. А. Виды административной деятельности органов и учреждений ФСин России: их классификация и сущность // Вестн. Владимир. юрид. ин-та. 2008. № 4 (9). С. 56-58.

${ }_{22}$ См.: Анискина Н. В. Классификация мер административного принуждения, применяемых сотрудниками ФСин России // Вестн. ин-та: преступление, наказание, исправление. 2019. Т. 13, № 2. С. 200-206.

${ }^{23}$ См.: Бахрах Д. Н. Административное принуждение в СССР, его виды и основные тенденции развития : дис. ... д-ра юрид. наук. Пермь, 1971.

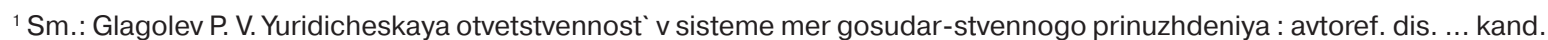
yurid. nauk. Orel, 2007. $18 \mathrm{~s}$.

${ }^{2}$ Sm.: Baxrax D. N., Rossijskij B. V., Starilov Yu. N. Administrativnoe pravo : ucheb. dlya vuzov. 2-e izd., izm. i dop. M., 2005. $800 \mathrm{~s}$.

${ }^{3} \mathrm{Sm}$.: Kaplunov A. I. Administrativnoe prinuzhdenie, primenyaemoe orga-nami vnutrennix del (sistemno-pravovoj analiz) : dis. ... d-ra yurid. nauk. M., 2005. $498 \mathrm{~s}$.

${ }^{4} \mathrm{Sm}$.: Sarsenov K. M. Gosudarstvennoe prinuzhdenie i ego realizaciya v deya-tel'nosti organov vnutrennix del : avtoref. dis. ... kand. yurid. nauk. SPb., 1996. $196 \mathrm{~s}$.

${ }^{5}$ Sm.: Trubeczkoj E. N. Lekcii po e'nciklopedii prava. M., 1917. 227 s.

${ }^{6} \mathrm{Sm}$.: Zhizhilenko A. A. Nakazanie: ego ponyatie i otlichie ot drugix pravooxranitel'ny’x sredstv. Petrograd, 1914. $684 \mathrm{~s}$.

7 Sm.: Nizhnik N. S. Policejsko-pravovaya teoriya: osnovny`e e'tapy stanovle-niya v Rossii // Gosudarstvo i pravo: e'volyuciya, sovremennoe sostoyanie, perspektivy' razvitiya (navstrechu 300-letiyu rossijskoj policii) : materialy` mezhdunar. nauch.-teoret. konf. (g. Sankt-Peterburg, 28 aprelya 2016 g.) : v 2 t. / pod red. N. S. Nizhnik. SPb., 2016. T. 2. S. 230 ${ }^{8} \mathrm{Sm}$.: Tarasov N. K. "Gosudarstvennoe prinuzhdenie»: traktovka definicii v yuridicheskoj literature koncza XIX - nachala XX veka // Pravo i gosudar-stvo: problemy` metodologii, teorii i istorii : materialy` VIII Vseros. nauch.-prakt. konf. / red. kol.: L. V. Karnaushenko, A. A. Shvecz, E. A. Pushka-rev i dr. Krasnodar, 2019. S. 287.

${ }^{9} \mathrm{Sm}$.: On zhe. Fenomen «prinuzhdenie»: podxody" k opredeleniyu sushhnosti v sovremennoj gumanitarnoj nauke // Tam zhe. S. 296. 
${ }^{10} \mathrm{Sm}$.: Nazimov A. E. Lekcii po policejskomu pravu / pod red. stud. B. F. Lemesha-Lemeshinskogo. Odessa, 1903. S. 145146.

${ }^{11} \mathrm{Sm}$.: Ivanovskij V. V. Uchebnik administrativnogo prava (Policejskoe pravo. Pravo vnutrennego upravleniya). 3-e izd. Kazan', 1908. S. 298

${ }^{12}$ Sm.: Palibin M. N. Povtoritel'ny’j kurs policejskogo prava. 2-e izd. SPb., 1900. 255 s.

${ }^{13} \mathrm{Sm}$.: Demidov P. V. Chastnoe pravovoe prinuzhdenie kak kategoriya sovremen-noj teorii prava: nauchny`e i prakticheskie problemy' : dis. ... kand. yurid. nauk. N. Novgorod, 2005. S. 78.

${ }^{14} \mathrm{Sm}$.: Makarejko N. V. Gosudarstvennoe prinuzhdenie kak sredstvo obespeche-niya obshhestvennogo poryadka : dis. ... kand. yurid. nauk. N. Novgorod, 1996. S. 102.

${ }^{15} \mathrm{Sm}$.: Annenkov A. Yu. Gosudarstvenno-pravovoe prinuzhdenie: filosofsko-pravovy`e osnovy` ponimaniya // E`konom. i yurid. nauki. 2017. № 3-2. S. 52-60.

${ }^{16} \mathrm{Sm}$.: Vasechko A. A. Mezhdunarodny`j dogovor kak istochnik vnutrigosudar-stvennogo prava : dis. ... kand. yurid. nauk. M., 2008.

${ }_{17} \mathrm{Sm}$.: Chashnikov V. A. Gosudarstvenno-pravovoe prinuzhdenie: obshheteoreti-cheskie voprosy` : dis. ... kand. yurid. nauk. Ekaterinburg, 2006. S. 87.

${ }^{18} \mathrm{Sm} .:$ Agapov A. B. Administrativnoe pravo : ucheb. dlya bakalavriata i ma-gistratury` : v 2 t. M., 2019. T. 1. Obshhaya chast'. $472 \mathrm{~s}$.

${ }^{19} \mathrm{Sm} .:$ Volkov A. M. Administrativnoe pravo Rossii : ucheb. M., 2019. $328 \mathrm{~s}$.

${ }^{20} \mathrm{Sm}$.: Nagorny $\times$ R. V. Administrativno-pravovoe prinuzhdenie // Sushhnost’, formy` i metody` realizacii ispolnitel'noj vlasti : ucheb. posobie dlya ma-gistratury" po napravleniyu podgotovki «Yurist v sfere gosudarstvennogo upravleniya» / Vasil'eva Ya. V. i [dr.]. Vologda, 2019. S. 133-155.

${ }^{21} \mathrm{Sm}$.: Mel'nikova N. A. Vidy' administrativnoj deyatel'nosti organov i uchrezhdenij FSIN Rossii: ix klassifikaciya i sushhnost' // Vestn. Vladimir. yurid. in-ta. 2008. № 4 (9). S. 56-58.

${ }^{22} \mathrm{Sm}$.: Aniskina N. V. Klassifikaciya mer administrativnogo prinuzhdeniya, primenyaemy`x sotrudnikami FSIN Rossii // Vestn. in-ta: prestuplenie, nakazanie, ispravlenie. 2019. T. 13, № 2. S. 200-206.

${ }^{23} \mathrm{Sm}$.: Baxrax D. N. Administrativnoe prinuzhdenie v SSSR, ego vidy` i osnovny’e tendencii razvitiya : dis. ... d-ra yurid. nauk. Perm', 1971. 